九州大学学術情報リポジトリ

Kyushu University Institutional Repository

\title{
Measurement of solubilities for rhodium complexes and phosphine ligands in supercritical carbon dioxide
}

Shimoyama, Yusuke

Department of Chemical Engineering, Faculty of Engineering, Kyushu University

Sonoda, Masahiro

Department of Chemical Engineering, Faculty of Engineering, Kyushu University

Miyazaki, Kaoru

Department of Chemical Engineering, Faculty of Engineering, Kyushu University

Higashi, Hidenori

Division of Material Engineering, Graduate School of Natural Science \& Technology, Kanazawa University

他

http://hdl. handle. net/2324/12537

出版情報：Journal of Supercritical Fluids. 44 (3)，pp.266-272，2008-04. Elsevier バージョン：

権利関係 : (C) 2007 Published by Elsevier B.V. 


\section{Revised manuscript submitted to The Journal of Supercritical Fluids (SUPFLU-D-07-00060)}

Measurement of solubilities for rhodium complexes and phosphine ligands in supercritical carbon dioxide

Yusuke Shimoyama $^{\mathrm{a}, *}$, Masanori Sonoda ${ }^{\mathrm{a}}$, Kaoru Miyazakia ${ }^{\mathrm{a}}$, Hidenori Higashi ${ }^{\mathrm{b}}$, Yoshio Iwai $^{\mathrm{a}}$ and Yasuhiko Arai ${ }^{\mathrm{a}}$

${ }^{a}$ Department of Chemical Engineering, Faculty of Engin eering, Kyushu University 744 Motooka Nishi-ku, Fukuoka 819-0395, JAPAN

${ }^{\mathrm{b}}$ Division of Material Engineering, Graduate School of Natural Science \& Technology, Kanazawa University, Kakuma-machi Kanazawa-shi, Ishikawa 920-1192, JAPAN

* To whom correspondence should be addressed.

Tel \& Fax: +81-92-802-2771, E-mail: yshimo@chem-eng.kyushu-u.ac.jp 


\begin{abstract}
The solubilities of phosphine ligands and rhodium $(\mathrm{Rh})$ complexes in supercritical carbon dioxide were measured by circulation method with a Fourier Transform Infrared (FT-IR) spectroscopy at 320 and $333 \mathrm{~K}$ and several pressures. Triph enylphosphine(TPP) and tris( $p$-trifluoromethylphenyl)phoshine(TTFMPP) were selected as ligands which compose the Rh complex. The solubilities of the fluorinated ligands and complexes were compared with those of the non-fluorinated compounds. It was found that the solubilities of $\mathrm{Rh}$ complexes are enhanced by introducing trifluoromethyl group to the ligand. The experimental data was correlated by Chrastil equation. The correlated results are in good agreement with the experimental data. Furthermore, the solvation numbers of carbon dioxide around the ligands and $\mathrm{Rh}$ complexes were obtained from the slope of Chrastil equation. The solvation number for the fluorinated compounds are larger than those for the non-fluorinated compounds.
\end{abstract}

Keywords : solubility; supercritical carbon dioxide; phosphine ligand; Rh complex; fluorination 


\section{Introduction}

Supercritical fluid technologies have been actively applied and used commercially for extraction, fractionation, and purification in chemical, food and pharmaceutical industries. In particular, supercritical carbon dioxide $\left(\mathrm{SCCO}_{2}\right)$ whose critical temperature and pressure are $304.2 \mathrm{~K}$ and $7.3 \mathrm{MPa}$ has been frequently used because it can reach the supercritical state under relatively mild conditions. Also carbon dioxide is cheap, stable and inflammable.

$\mathrm{SCCO}_{2}$ has also received much attention as a reaction medium. A large number of studies concerning the organic synthesises in $\mathrm{SCCO}_{2}$ have been reported [1-3]. In these $\mathrm{SCCO}_{2}$ processes, there has been a problem that the catalysts generally used in organic synthes is es are hardly dissolved in $\mathrm{SCCO}_{2}$. The enhancements of catalyst solubilities in $\mathrm{SCCO}_{2}$ are needed for the increase of the reaction rates. Some studies have reported that the solubilities in $\mathrm{SCCO}_{2}$ are enhanced by the fluorinations of the solutes for the metal complexes [4-6], ligands [7], polymers [8], pharmaceuticals [9] and surfactants [10]. Tsukahara et al. [6] have reported the solubilities of uranyl $\beta$-diketonato complexes in $\mathrm{SCCO}_{2}$ at $40{ }^{\circ} \mathrm{C}$ and $10.0-25.0 \mathrm{MPa}$. Acetylacetonate, trifluoroacetylacetonate and hexafluoroacetylacetonate were selected as the ligands. It has been reported that the solubilities of the fluorinated complexes in which the ligands were trifluoroacetylacetonate and hexafluoroacetylacetonate were larger than those of the complex with acetylacetonate. The solubilities of the fluorinated phosphates in $\mathrm{SCCO}_{2}$ at 300.0 - 330.0 K have been also reported by Wagner et al [7].

Fujita et al. [11,12] have reported that the Rh complexes with the fluorinated phosphate ligand was more effective in the hydroformylation of the dienes to dialdehydes in $\mathrm{SCCO}_{2}$ than those with non-fluorinated ligands. $\mathrm{Ru}$ complexes with the 
fluorinated phosphine have been adopted to the hydrogenation of the unsaturated aldehyde by Zhao et al. [13] It is very important and useful for these reaction design to understand the relationships between the solubility increase of these catalyst by the phosphate ligand fluorination and the reaction promotion. Unfortunately, no experimental data of the solubilities for these catalysts in supercritical carbon dioxide is available.

In this work, the solubility data of the phosphine ligands and $\mathrm{Rh}$ complexes in $\mathrm{SCCO}_{2}$ are reported. The measurements of the solubilities were performed by circulation method with a Fourier Transform Infrared (FT-IR) spectroscopy at 320 and $333 \mathrm{~K}$ and $8.96-15.94$ MPa. Triphenylphosphine(TPP) and tris $(p$-trifluoromethylphenyl -phosphine (TTFMPP) were selected as the phosphine ligands which compose Rh complexes. The solubilities of the fluorinated ligands and $\mathrm{Rh}$ complexes were compared with those of the non-fluorinated compounds. Moreover, the experimental data was correlated by the Chrastil equation [14]. The solvation numbers of carbon dioxide around the solutes were obtained from the slope of Chrastil equation.

\section{Experiment}

\subsection{Materials}

TPP was supplied by Aldrich Co. with a purity higher than 99\%. TTFMPP was supplied by Azmax Co. with a purity higher than $97 \%$ by a gas chromatograph analys is. Carbonylhydridtris(triphenylphosphine)rhodium(Rh-TPP) was supplied by Wako Co. Carbon dioxide was supplied by Sumitomo Seika Co. with a purity higher than $99.9 \%$. The substances were used without further purification. Structural formulas of phosphine ligands and $\mathrm{Rh}$ complex are shown in Figures 1 and 2, respectively. As Rh complex 
composed of TTFMPP (Rh-TTFMPP) is not commercially available, Rh-TTFMPP was synthesized in this work. (Acetylacetonato)-dicarbonylrhodium(I) purchased from Wako Co. was used for the synthesis of Rh-TTFMPP. The synthesis procedures of Rh-TTFMPP are described in the subsequent section.

\subsection{Apparatus and procedure}

A circulation-type apparatus combined with on-line FT-IR spectroscope is shown in Figure 3. The apparatus in this work was similar to that in the previous work [15-17] and the detail descriptions of the apparatus have been given there. The circulation part of the apparatus equipped the circulation pump(9), FT-IR spectroscope(10) and equilibirium cell(11) with sapphire windows. The circulation part was immersed in a water bath(14) and controlled in the focused temperature with in $\pm 0.1 \mathrm{~K}$. The pressures

in the system were maintained within $\pm 0.25 \mathrm{MPa}$ during the measurements. The FT-IR spectroscope(10) was adopted to measure the compositions of the solute in supercritical fluid phase.

The relationships between the molarities of the solute and the absorbance of the specific peak were calibrated with Lambert - Beer law by the following procedure before the solubility measurements. The known amounts of the ligand or complex were dissolved in supercritical carbon dioxide. It was confirmed the formation of the homogenous phase with the windows of the cell. Then the absorbances of the specific peak were measured with FT-IR spectroscope and the calibration curves were formed. In the measurements of solubilities, at first, the solute was set in to the equilibrium cell(11). After sealing the cell, carbon dioxide was supplied from a cylinder(1) and 
liquefied through a cooling unit(4). The liquefied carbon dioxide was provided to the system by a feed pump(5). The carbon dioxide achieved to the supercritical state through the preheating coil(7) and entered into the equilibrium cell(11). After the pressure was reached to the desired condition, the fluid in the system was circulated. The compositions of the solute in $\mathrm{SCCO}_{2}$ were analyzed with the FT-IR spectroscope(10). For Rh-TTFMPP, the synthes is of this complex was carried out before the solubility measurements. (Acetylacetonato)-dicarbonylrhodium(I) and TTFMPP in mole ratio $1: 4$ were located in the equilibrium cell. Then, the system was reached to the desired conditions by the operations described above. The synthesis was performed at $333 \mathrm{~K}$ and $4.0 \mathrm{MPa}$ for $4-14 \mathrm{hs}$.

In the IR analyses, FT-IR spectroscope was purged with dry $\mathrm{N}_{2}$. The IR spectra were measured at $4 \mathrm{~cm}^{-1}$ wavenumber resolution to obtain the desired signal-to-noise ratio. The optical cell was made from SUS316 and the optical path length was $5.0 \mathrm{~mm}$. The windows of the optical cell were made of $\mathrm{ZnSe}$ and the thickness was $8.0 \mathrm{~mm}$. The optical cell was maintained to the desired temperatures with water pumped from a water bath(14). The absorption spectra of pure carbon dioxide at each temperatures was utilized as the reference spectra. The IR spectra of the solutes were determined by subtracting those of pure carbon dioxide from those of the mixture of solute and carbon dioxide. The specific peaks of the solutes (Rh-TPP: around $3064 \mathrm{~cm}^{-1}, \mathrm{Rh}$-TTFMPP: around $1990 \mathrm{~cm}^{-1}$, TPP: around $3064 \mathrm{~cm}^{-1}$, TTFMPP: around $960 \mathrm{~cm}^{-1}$ ) were adopted to determine the compositions of the solutes in $\mathrm{SCCO}_{2}$. Figure 4 shows the IR spectra for TTFMPP and Rh-TTFMPP at $320 \mathrm{~K}$ and several pressures. The saturated state was confirmed by the absorbance variation as time. As an example, the absorbance variations in $3064 \mathrm{~cm}^{-1}$ as time for TPP at $320 \mathrm{~K}$ and $15.91 \mathrm{MPa}$ are shown in Figure 5. 
The saturated solubilities were determined from the constant absorbance as shown by

solid line in Figure 5. The molarities in $\mathrm{mol} \mathrm{L}^{-1}$ of the solute in supercritical carbon dioxide were determined using the absorbance from the calibration curves. Then, the obtain ed solubitlities were converted to a mole fraction basis using the densities of pure carbon dioxide calculated with the equation of state [18]. The accuracies of the solubility data were within $5 \%$ for the ligands and $10 \%$ for the Rh complexes.

The measured conditions were at 320 and $333 \mathrm{~K}$ and $8.96-15.94 \mathrm{MPa}$. From the phase behavior with the view cell, the vapor-liquid equilibria were observed for TPP at $333 \mathrm{~K}$ below 10.5 MPa and TTFMPP at all temperatures and pressures. For TPP at the other conditions, the phase states were the solid-vapor equilibria. The phase behavior for Rh-TPP and Rh-TTFMPP was also the solid-vapor equilibria at the temperatures and pressure focused in this work.

\section{Correlation}

The experimental solubility data of the solutes in $\mathrm{SCCO}_{2}$ was correlated with Chrastil equation [14]. This equation given by the following can explain simply the relation between the solubilities of solutes in $\mathrm{SCCO}_{2}$ and the densities of carbon dioxide.

$$
\ln S_{2}=k \ln \rho_{1}+C
$$

where $S_{2}$ is the solubility of the solute in $\mathrm{SCCO}_{2}$ in $\mathrm{g} \mathrm{L}^{-1}, \rho_{1}$ is the density of carbon dioxide in $\mathrm{g} \mathrm{L}^{-1} . k$ corresponds to the number of carbon dioxide molecules associated with the solute. $C$ is the temperature dependent constant related to the enthalpies of vaporization and solvation. The densities of carbon dioxide were calculated by the equation of state proposed by Huang et al. [18]. The parameters $k$ and $C$ were determined from the solubility data obtained in this work. 


\section{Results and disc ussion}

The experimental results for solubilities of ligands TPP and TTFMPP at 320 and 333 $\mathrm{K}$ are shown in Table 1 and Figure 6. Wagner et al. [7] have also reported the solubility data of TPP and TTFMPP in $\mathrm{SCCO}_{2}$ at $320 \mathrm{~K}$. The comparisons of the solubility data between this work and the literature can be explain ed from Figure 6. The solubility data for TPP at $320 \mathrm{~K}$ in this work are higher than those in the literature. For TTFMPP at 320 $\mathrm{K}$, the data in this work are in good agreement with the literature data in the range of 10.5 - 11.0 MPa. As shown in Figure 6, the solubilities of fluorinated TTFMPP are 2.0 -9.8 times at $320 \mathrm{~K}$ and $2.4-7.6$ times at $333 \mathrm{~K}$ higher than those of non-fluorinated TPP.

For Rh-TPP and Rh-TTFMPP, the solubility data obtained in this work are shown in Table 2 and Figure 7. It is found that the solubilities of Rh complex are much lower than those of their ligands by $10^{-3}-10^{-1}$. At $333 \mathrm{~K}$, the solubilities of Rh-TTFMPP with fluorinated ligands are about 3 - 30 times higher than those of Rh-TPP with non-fluorinated ligands. These tendencies are the same as in the case of the phosphine ligands. The solubility enhancements for Rh-complexes by the fluorination of the ligands are larger than those of the ligands. The increase ratios of $\mathrm{Rh}$ complex solubilities by the fluorination were compared with those of other metal complexes as shown in Table 3. For $\mathrm{Rh}$ complexes in this work, the ratio is higher than those of the sodium and uranyl complexes and lower than those of the copper, nickel and cobalt complexes.

Figures 8 and 9 give the correlated results of the solubilities for the phosphine ligands and $\mathrm{Rh}$ complexes in $\mathrm{SCCO}_{2}$, respectively. Linear relationships between the solubilities and the densities of carbon dioxide were successfully obtained for all solutes at each 
temperature. The values of $k$ and $C$ in equation (1) determined in this work are listed in Table 4. The parameter $k$ in Chrastil equation means the solvation number of the solvent molecule around the solute molecule. The knowledge of the soluvation is very important to understand the mechanism of the solubility increase by the fluorination. The values of $k$ for the fluorinated ligands at 320 and $333 \mathrm{~K}$ and fluorinated complexes at $333 \mathrm{~K}$ are 1.7, 1.4 and 5.0 times larger than those for non-fluorinated compounds, respectively. This means that the fluorinated ligand or complex molecule in teracts more strongly with carbon dioxide molecule by the fluorinations. It is considered that the increases of $k$ correspond to the tendencies of the solubility increase by the fluorination of the phosphine ligands. These results suggest that the solubilities of phosphine ligands and $\mathrm{Rh}$ complexes are dominated by the solvation of carbon dioxide around the solutes.

\section{Conclusion}

The solubilities of the phosphine ligands and $\mathrm{Rh}$ complexes in $\mathrm{SCCO}_{2}$ were measured by circulation method with a FT-IR spectroscopy at 320 and 333 K. From the experimental data obtained in this work, that is demonstrated that the fluorinations of the phospine ligands enhance the solubilities of the Rh complexes. The experimental data obtained was correlated with Chrastil equation. The correlated results represent the experimental data with the linear relationships between the solubilities and the densities of carbon dioxide. The solvation numbers of carbon dioxide around the solutes were obtained from the correlations. The solvation numbers for the fluorinated ligands and $\mathrm{Rh}$ complexes were larger than those of the non-fluorinated compounds. These results can demonstrate that the increases of the solvation numbers correspond to the solubility enhancements by the fluorination of the ligands. 


\section{Acknowledgment}

The present study was supported in part by a Grant-in-Aid for Scientific search (B), 17360376, 2004, and Grant-in-Aid for the 21st century center of excellent (COE) program, "Functional Innovation of Molecular Informatics" from the Ministry of Education, Science, Sports and Culture, Japan.

\section{Reference}

[1] R. Liu, F. Zhao, S. Fujita, M. Arai, Selective hydro genation of citral with transition metal complexes in supercritical carbon dioxide, Appl. Cataly. A 316 (2007) 127-133.

[2] B.M. Bhanage, Y. Ikushima, M. Shirai, M. Arai, Heck reactions in supercritical carbon dioxide using organometallic complex catalysts, High Pressure Res. 20 (2001) 131-142.

[3] B. M. Bhanage, S. Fujita, Y. Ikushima, M. Arai, Syn thesis of dimethyl carbonate and glycols from carbon dioxide, epoxides, and methanol using heterogeneous basic metal oxide catalysts with high activity and selectivity, Appl. Cataly. A 219 (2001) 259-266.

[4] K.E. Laintz, C.M. Wai, C.R. Yonker, R.D. Smith, Solubility of fluorinated metal diethyldithiocarbamates in supercritical carbon dioxide, J. Supercritical Fluids 4 (1991) 194-198.

[5] N. Dahmen, P. Griesheimer, P. Makarczyk, S. Pitter, O. Walter, Solubility of trans- $\mathrm{Co}_{2}(\mathrm{CO})_{6}\left[3,5-\mathrm{bis}\left(\mathrm{CF}_{3}\right) \mathrm{C}_{6} \mathrm{H}_{3} \mathrm{P}\left(i-\mathrm{C}_{3} \mathrm{H}_{7}\right)_{2}\right]$ in dense carbon dioxide, J. Org. Chem. 690 (2005) 1467-1473.

[6] T. Tsukahara, Y. Kachi, Y. Kayaki, T. Ikariya, Y. Ikeda, Spectrophotometric study 
on solubility of $\mathrm{UO}_{2}(\beta \text {-diketonato })_{2}$ dmso complexes $(\beta$-diketonate $=$ acetylacetonate, trifluoroacetylacetonate, hexafluoroacetylacetonate; dmso = dimethyl sulfoxide) in supercritical carbon dioxide, J. Supercritical Fluids 39 (2006) 6-12.

[7] K.-D. Wagner, N. Dahmen, E. Dinjus, Solubility of triphenylphosphine, tris $(p-$ trifluorophenyl)phosphine, tris(pentafluorophenyl)phosphine, and tris( $p$-trifluoro -methylphenyl)phosphine in liquid and supercritical carbon dioxide, J. Chem. Eng. Data 45 (2000) 672-677.

[8] B. Baradie, M.S. Shoichet, Z Shen, M.A. McHugh, L. Hong, Y. Wang, J.K. Johnson, E.J. Beckman, R.M. Enick, Synthesis and solubility of linear poly(tetrafluoro -ethylene-co-vinyl acetate) in dense $\mathrm{CO}_{2}$ : Experimental and molecular modeling results, Macromolecules 37 (2004) 7799-7807.

[9] A. Laitinen, O. Jauhiainen, O. Aaltonen, Solubility of fluorinated pharmaceuticals in dense carbon dioxide, Org. Proc. Res. Dev. 4 (2000) 353-356.

[10] V. Martinez, S. Mecking, T. Tassaing, M. Besnard, S. Moisan, F. Cansell, C. Aymonier, Dendritic core-Shell macromolecules soluble in supercritical carbon dioxide, Macromolecules 39 (2006) 3978-3979.

[11] S. Fujita, S. Fujisawa, B.M. Bhanage, Y. Ikushima, M. Arai, Hydroformylation of 1,5-hexadiene catalyzed by rhodium complexes in sup ercritical carbon dioxide and in toluene: effects of fluorinated phosphane ligands and reaction conditions, Eur. J. Org. Chem. 13 (2004) 2881-2887.

[12] S. Fujita, S. Fujisawa, B.M. Bhanage, M. Arai, Rhodium - tris (3,5-bis (trifluoromethyl) phenyl) phsphine catalyzed hydroformylation of dienes to dialdehydes in supercritical carbon dioxide with high activity, Tetrahedron Lett. 45 
(2004) 1307-1310.

[13] F. Zhao, Y. Ikushima, M. Chatterjee, O. Sato, M. Arai, Hydrogenation of an $\alpha, \beta$-unsaturated aldehyde catalyzed with rutheniumcomplexes with different fluorinated phosphine compounds in supercritical carbon dioxide and conventional organic solvents, J. Sup ercritical Fluids 27 (2003) 65-72.

[14] J. Chrastil, Solubility of solids and liquid in supercritical gases, J. Phys. Chem. 86 (1982) 3016-3021.

[15] M. Yamamoto, Y. Iwai, T. Nakajima, Y. Arai, Fourier transform infrared study on hydrogen bonding species of carboxylic acids in supercritical carbon dioxide with ethanol, J. Phys. Chem. A 103 (1999) 3525-3529.

[16] Y. Iwai, D. Tanabe, M. Yamamoto, T. Nakajima, M. Uno, Y. Arai, FT-IR study on interactions between solutes and entrainers in supercritical carbon dioxide, Fluid Phase Equilibria 193 (2002) 203-216.

[17] Y. Iwai, M. Uno, H. Nagano, Y. Arai, Measurement of sulubilities of palmitic acid in supercritical carbon dioxide and entrainer effect of water by FTIR spectroscopy, J. Supercritical Fluids 28 (2004) 193-200.

[18] F.H. Huang, M.H. Li, L.L. Lee, K.E. Starling, F.T.H. Chung, An accurate equation of state for carbon dioxide, J. Chem. Eng. Jpn. 18 (1985) 490-496. 
Table 1 Solubilities of ligands(2) in supercritical carbon dioxide(1)

\begin{tabular}{|c|c|c|c|c|c|}
\hline \multicolumn{6}{|c|}{ Triphen ylphosphine (TPP) } \\
\hline$T[\mathrm{~K}]$ & $p[\mathrm{MPa}]$ & $y_{2}[-]$ & $T[\mathrm{~K}]$ & $p[\mathrm{MPa}]$ & $y_{2}[-]$ \\
\hline \multirow[t]{15}{*}{320} & 8.96 & 0.000042 & \multirow[t]{15}{*}{333} & 9.95 & 0.000039 \\
\hline & 9.99 & 0.000190 & & 10.55 & 0.000070 \\
\hline & 10.96 & 0.000457 & & 10.97 & 0.000095 \\
\hline & 11.98 & 0.000685 & & 11.49 & 0.000162 \\
\hline & 13.99 & 0.000922 & & 12.04 & 0.000228 \\
\hline & 15.91 & 0.00109 & & 12.50 & 0.000248 \\
\hline & \multirow[t]{9}{*}{17.76} & \multirow[t]{9}{*}{0.00130} & & 12.98 & 0.000340 \\
\hline & & & & 13.08 & 0.000443 \\
\hline & & & & 13.50 & 0.000462 \\
\hline & & & & 13.95 & 0.000558 \\
\hline & & & & 14.01 & 0.000648 \\
\hline & & & & 14.52 & 0.000776 \\
\hline & & & & 15.02 & 0.000870 \\
\hline & & & & 15.45 & 0.000949 \\
\hline & & & & 15.94 & 0.00102 \\
\hline \multicolumn{6}{|c|}{ Tris( $p$-trifluoromethylph enyl)phosphine (TTFMPP) } \\
\hline$T[\mathrm{~K}]$ & $p[\mathrm{MPa}]$ & $y_{2}[-]$ & $T[\mathrm{~K}]$ & $p[\mathrm{MPa}]$ & $y_{2}[-]$ \\
\hline \multirow[t]{14}{*}{320} & 9.01 & 0.000082 & 333 & 10.02 & 0.000094 \\
\hline & 9.20 & 0.000143 & & 10.50 & 0.000182 \\
\hline & 9.39 & 0.000174 & & 11.03 & 0.000303 \\
\hline & 9.67 & 0.000425 & & 11.47 & 0.000553 \\
\hline & 9.77 & 0.000472 & & 11.98 & 0.000925 \\
\hline & 9.87 & 0.000628 & & 12.44 & 0.001539 \\
\hline & 10.14 & 0.000923 & & 12.63 & 0.001869 \\
\hline & 10.52 & 0.00254 & & 12.75 & 0.00212 \\
\hline & 10.67 & 0.00327 & & 12.92 & 0.00241 \\
\hline & 10.78 & 0.00377 & & 13.05 & 0.00278 \\
\hline & 10.92 & 0.00447 & & 13.29 & 0.00339 \\
\hline & & & & 13.45 & 0.00384 \\
\hline & & & & 13.70 & 0.00450 \\
\hline & & & & 13.86 & 0.00491 \\
\hline
\end{tabular}


Table 2 Solubilities of Rh complexes(2) in supercritical carbon dioxide(1)

\begin{tabular}{|c|c|c|c|c|c|}
\hline \multicolumn{6}{|c|}{ Carbonylhydridotris(triphenylphosphine)rhodium (Rh-TPP) } \\
\hline$T[\mathrm{~K}]$ & $p[\mathrm{MPa}]$ & $y_{2} \times 10^{7}[-]$ & & & \\
\hline \multirow[t]{6}{*}{333} & 9.91 & 3.1 & & & \\
\hline & 10.96 & 3.7 & & & \\
\hline & 12.94 & 4.4 & & & \\
\hline & 14.87 & 5.8 & & & \\
\hline & 15.94 & 6.2 & & & \\
\hline & 16.93 & 6.6 & & & \\
\hline \multicolumn{6}{|c|}{ Rh-TTFMPP } \\
\hline$T[\mathrm{~K}]$ & $p[\mathrm{MPa}]$ & $y_{2} \times 10^{5}[-]$ & $T[\mathrm{~K}]$ & $p[\mathrm{MPa}]$ & $y_{2} \times 10^{5}[-]$ \\
\hline \multirow[t]{5}{*}{320} & 9.04 & 0.44 & 333 & 12.02 & 0.12 \\
\hline & 9.92 & 2.4 & & 12.85 & 0.44 \\
\hline & 10.96 & 9.9 & & 13.77 & 1.1 \\
\hline & 11.23 & 11.0 & & 14.94 & 1.9 \\
\hline & 11.90 & 14.0 & & 15.30 & 2.0 \\
\hline
\end{tabular}


Table 3 Increase ratios of metal complex(2) solubilities in supercritical carbon dioxide(1) by fluorination

\begin{tabular}{|c|c|c|c|c|}
\hline Metal complex & $y_{2}[-]$ & $T[\mathrm{~K}]$ & $p[\mathrm{MPa}]$ & Increase ratio of $y_{2}$ \\
\hline $\mathrm{Rh}(\mathrm{TPP})$ & $5.8 \times 10^{-7}$ & 333 & 14.87 & \\
\hline Rh(TTFMPP) & $1.9 \times 10^{-5}$ & 333 & 14.94 & 33 \\
\hline $\mathrm{Na}(\mathrm{DDC})[7]$ & $1.0 \times 10^{-5}$ & 323 & 15.2 & \\
\hline $\mathrm{Na}(\mathrm{FDDC})[7]$ & $3.1 \times 10^{-5}$ & 323 & 15.2 & 3.1 \\
\hline $\mathrm{Cu}(\mathrm{DDC})_{2}[7]$ & $7.3 \times 10^{-8}$ & 323 & 15.2 & \\
\hline $\mathrm{Cu}(\mathrm{FDDC})_{2}[7]$ & $6.1 \times 10^{-5}$ & 323 & 15.2 & 827 \\
\hline $\mathrm{Ni}(\mathrm{DDC})_{2}[7]$ & $5.7 \times 10^{-8}$ & 323 & 15.2 & \\
\hline $\mathrm{Ni}(\mathrm{FDDC})_{2}[7]$ & $4.8 \times 10^{-5}$ & 323 & 15.2 & 847 \\
\hline $\mathrm{Co}(\mathrm{DDC})_{3}[7]$ & $1.6 \times 10^{-7}$ & 323 & 15.2 & \\
\hline $\mathrm{Co}(\mathrm{FDDC})_{3}[7]$ & $5.3 \times 10^{-5}$ & 323 & 15.2 & 333 \\
\hline $\mathrm{UO}_{2}(\mathrm{ACAC})[9]$ & $6.9 \times 10^{-5}$ & 313 & 15.0 & \\
\hline $\mathrm{UO}_{2}$ (TFA) [9] & $3.8 \times 10^{-4}$ & 313 & 15.0 & 5.4 \\
\hline
\end{tabular}

DDC: diethyldithiocabamate, FDDC: bis(trifluoroethyl)dithiocarbamate,

ACAC: acetylacetonate, TFA: trifluoroacetylacetonate 
Table 4 Values of parameters $k$ and $C$ in Chrastil equation [14]

\begin{tabular}{lccc}
\hline Solute & $T[\mathrm{~K}]$ & $k[-]$ & $C[-]$ \\
\hline TPP & 320 & 4.72 & -29.6 \\
& 333 & 5.15 & -31.8 \\
TTFMPP & 320 & 7.98 & -47.3 \\
& 333 & 7.15 & -41.9 \\
Rh-TPP & 333 & 1.88 & -17.0 \\
Rh-TTFMPP & 320 & 6.27 & -39.2 \\
& 333 & 9.35 & -60.8 \\
\hline
\end{tabular}




\section{Figure Captions}

Figure 1 Structural formulas of ligands: (a) Triphenylphosphine ( TPP ), (b) Tris( $p$-trifluoromethylph enyl)phosphine (TTFMPP).

Figure 2 Structural formula of Rh complex.

Figure 3 Experimental apparatus for solubility measurement in supercritical carbon dioxide: 1. Gas Cylinder, 2. Dryer, 3. Filter, 4. Cooling Unit, 5. Feed Pump, 6. Safety Valve, 7. Preheating Coil, 8. Check Valve, 9. Circulation Pump, 10. FT-IR, 11. Equilibrium Cell, 12. Flexible Heater, 13. Trap, 14. Water Bath, 15. Pressure Meter, 16. Digital Pressure Meter, V2. Back Pressure Regulator, V11. Expansion Valve, V1,V3-V10. Stop Valve.

Figure 4 IR spectra of (a) TTFMPP at $320.0 \mathrm{~K},(-, \cdots \cdots \cdots \cdots \cdots \cdots$

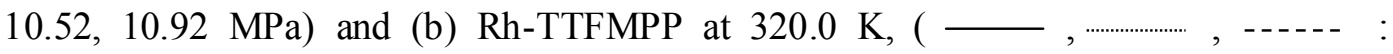
$9.92,10.96,11.90 \mathrm{MPa})$.

Figure 5 Absorbance variation as time for $\mathrm{TPP}$ in $\mathrm{SCCO}_{2}$ at $333 \mathrm{~K}$ and $15.94 \mathrm{MPa}$ : Absorbance at each time; $(\bigcirc)$, Averaged absorbance for determination of solubilities; $(-)$. 
Figure 6 Solubilities of phosphine ligands (2) in $\mathrm{SCCO}_{2}(1)$ : $\operatorname{TPP}(2)$; this work $(\bigcirc, \triangle: 320$ and $333 \mathrm{~K})$, Wagner et al. [7] ( $: 320 \mathrm{~K})$, $\operatorname{TTFMPP}(2)$; this work ( $\square, \nabla: 320$ and $333 \mathrm{~K})$, Wagner et al. [7] ( $\square: 320 \mathrm{~K})$.

Figure 7 Solubilities of $\mathrm{Rh}$ complexes(2) in $\mathrm{SCCO}_{2}(1): \operatorname{Rh}-\mathrm{TPP}(2) ;(\bigcirc: 333 \mathrm{~K})$, Rh-TTFMPP(2); this work ( $\triangle, \square: 320$ and $333 \mathrm{~K})$.

Figure 8 Correlated results of solubilities of phospine ligands(2) in $\mathrm{SCCO}_{2}(1)$ : Experimental data; TPP(2); $(\bigcirc, \triangle: 320$ and $333 \mathrm{~K})$, TTFMPP(2); $(\square, \nabla: 320$ and $333 \mathrm{~K})$, Correlated results ( - ).

Figure 9 Correlated results of solubilities of $\mathrm{Rh}$ complex ligands(2) in $\mathrm{SCCO}_{2}(1)$ : Experimental data; Rh-TPP(2); $\bigcirc: 333 \mathrm{~K})$, Rh-TTFMPP(2); this work $(\triangle, \square: 320$ and $333 \mathrm{~K})$, Correlated results ( - ). 
(a)<smiles>c1ccc(P(c2ccccc2)c2ccccc2)cc1</smiles>

(b)<smiles>FC(F)(F)c1ccc(P(c2ccc(C(F)(F)F)cc2)c2ccc(C(F)(F)F)cc2)cc1</smiles>

Figure 1 


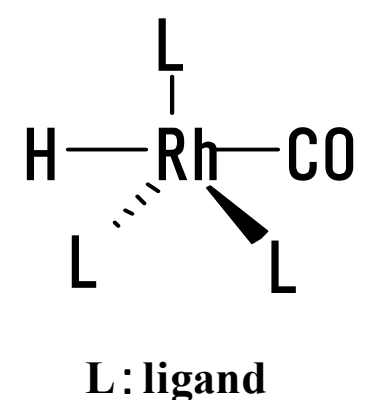

Figure 2 


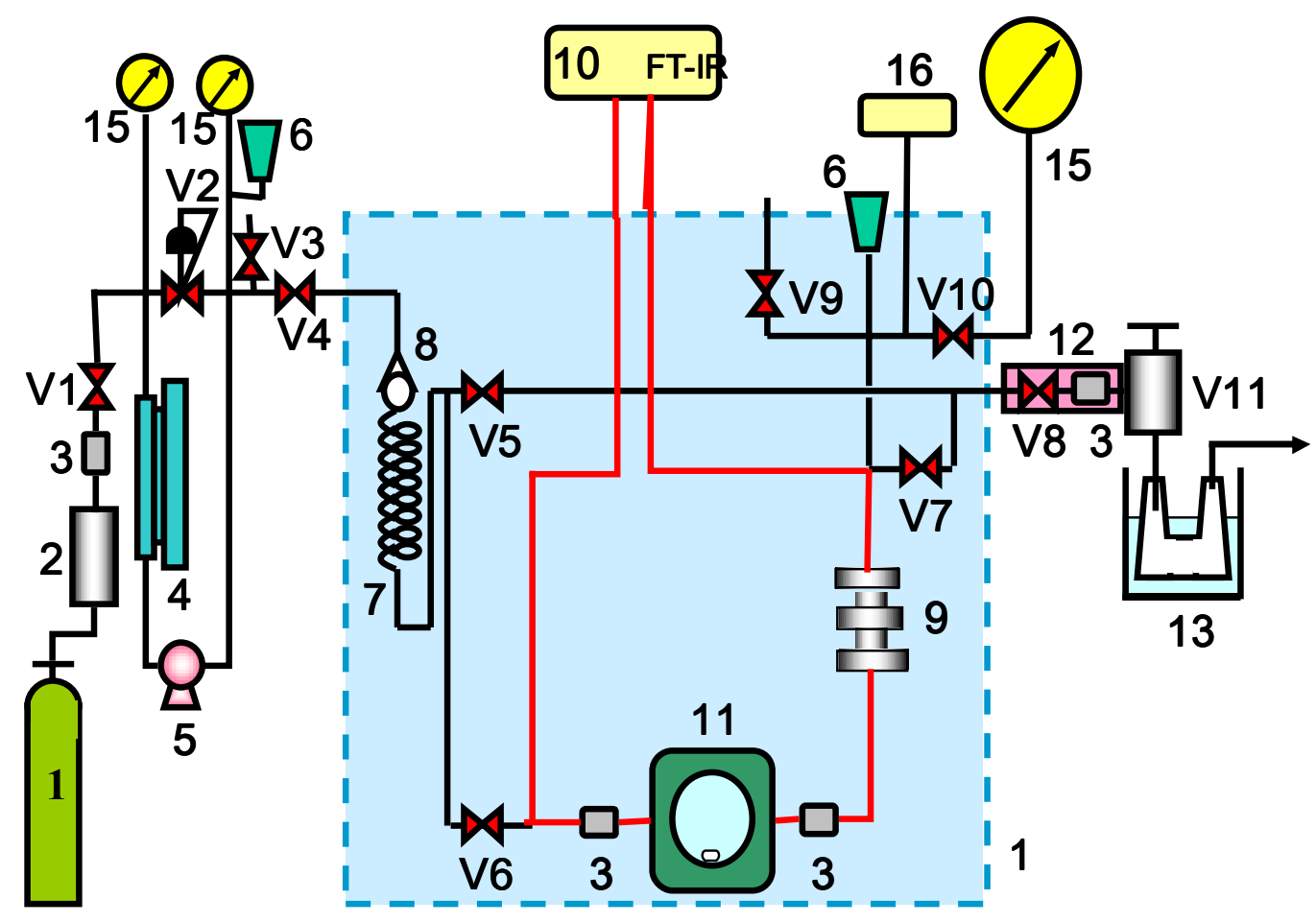

Figure 3 
(a)

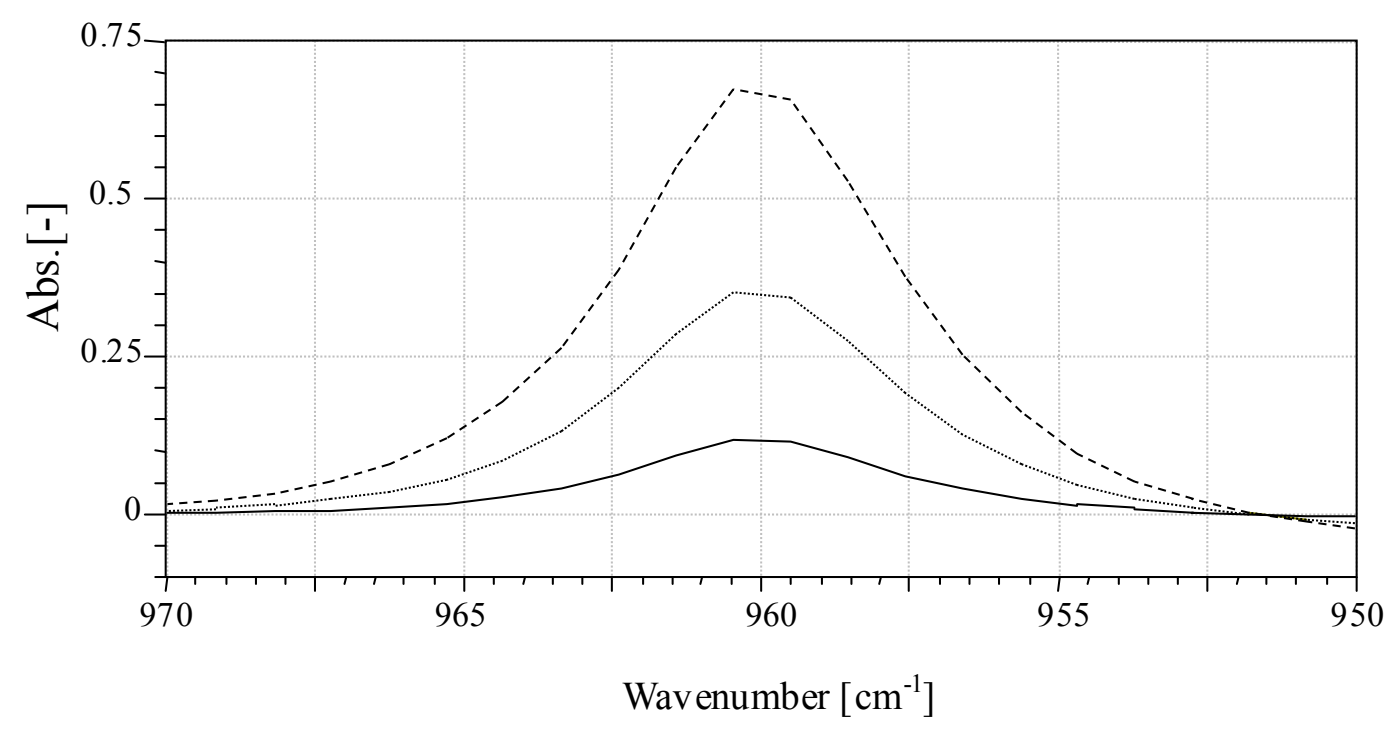

(b)

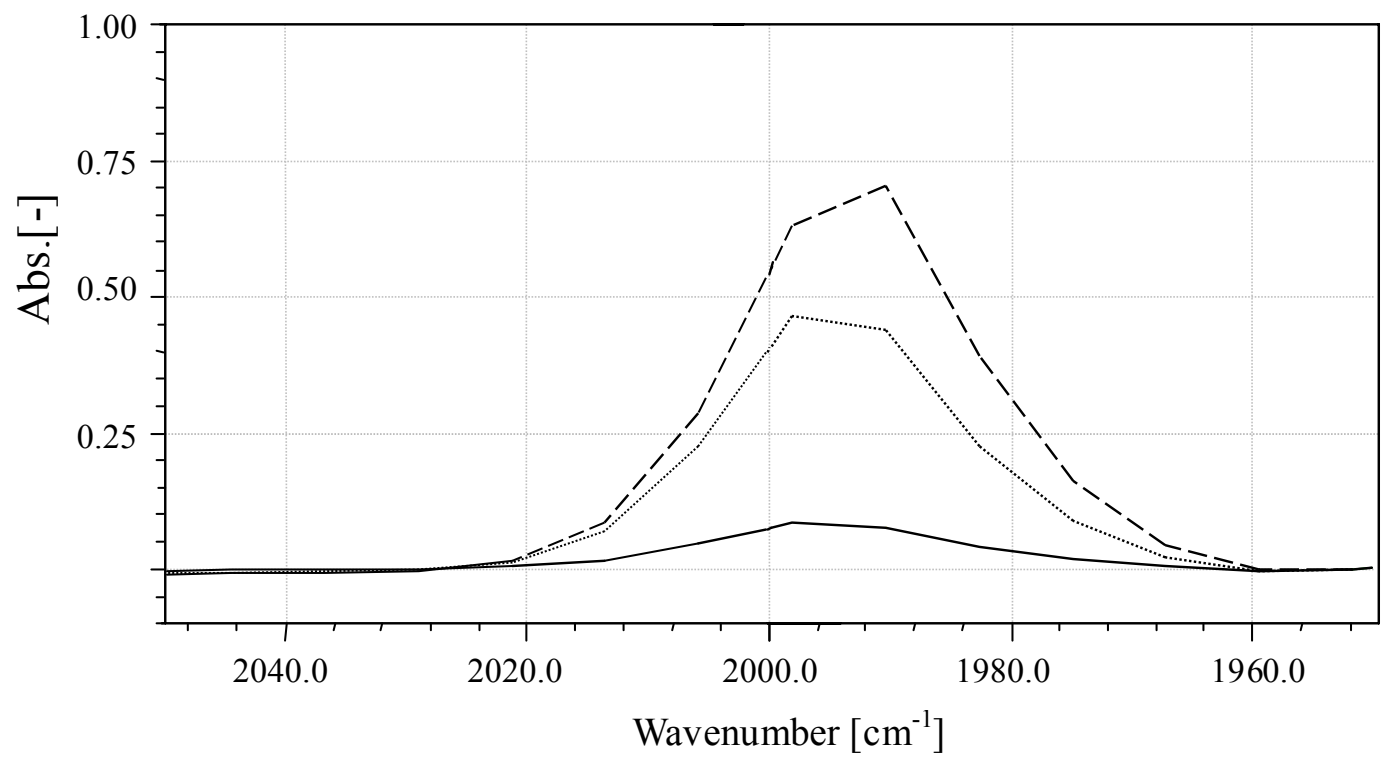

Figure 4 


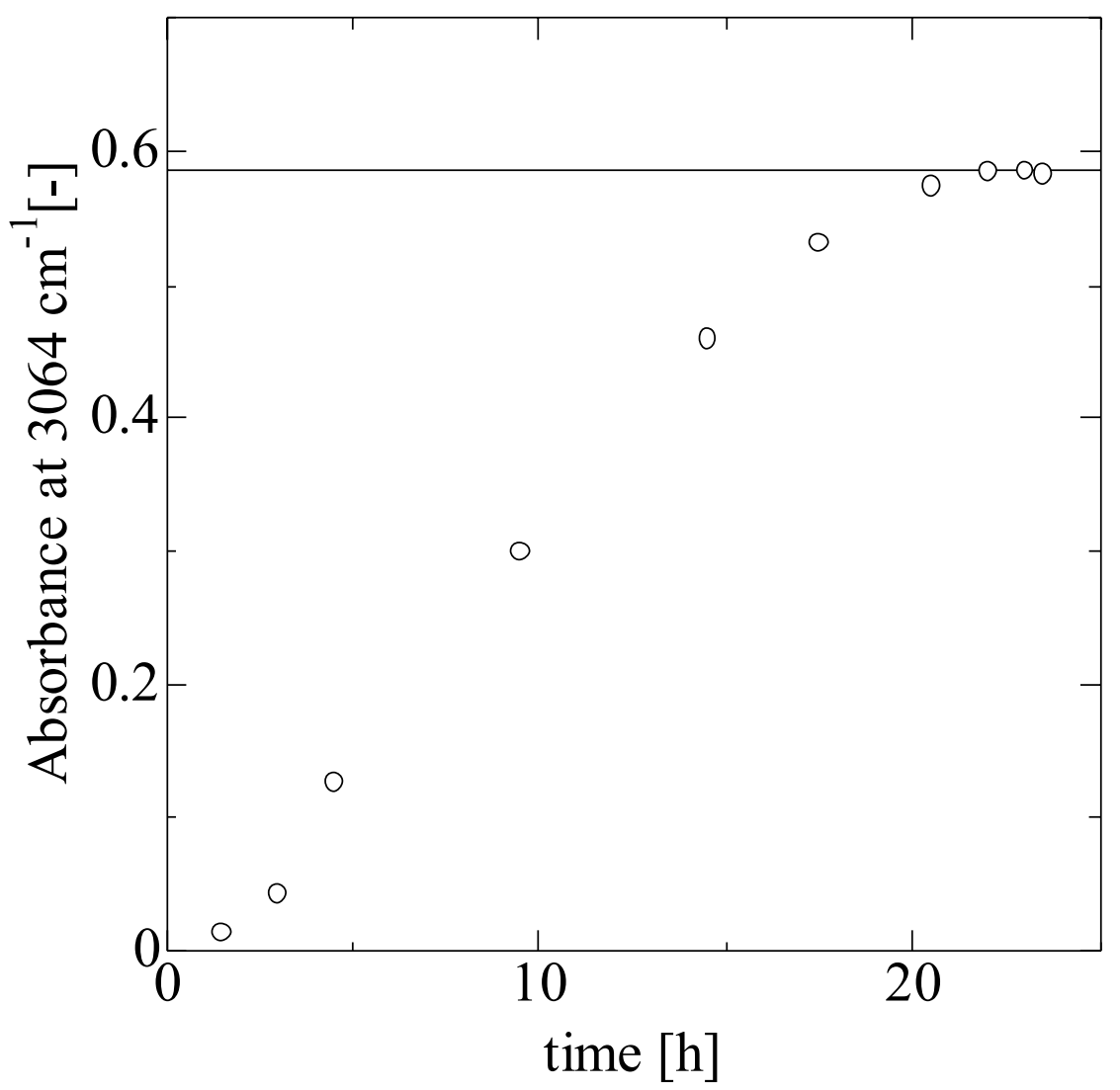

Figure 5 


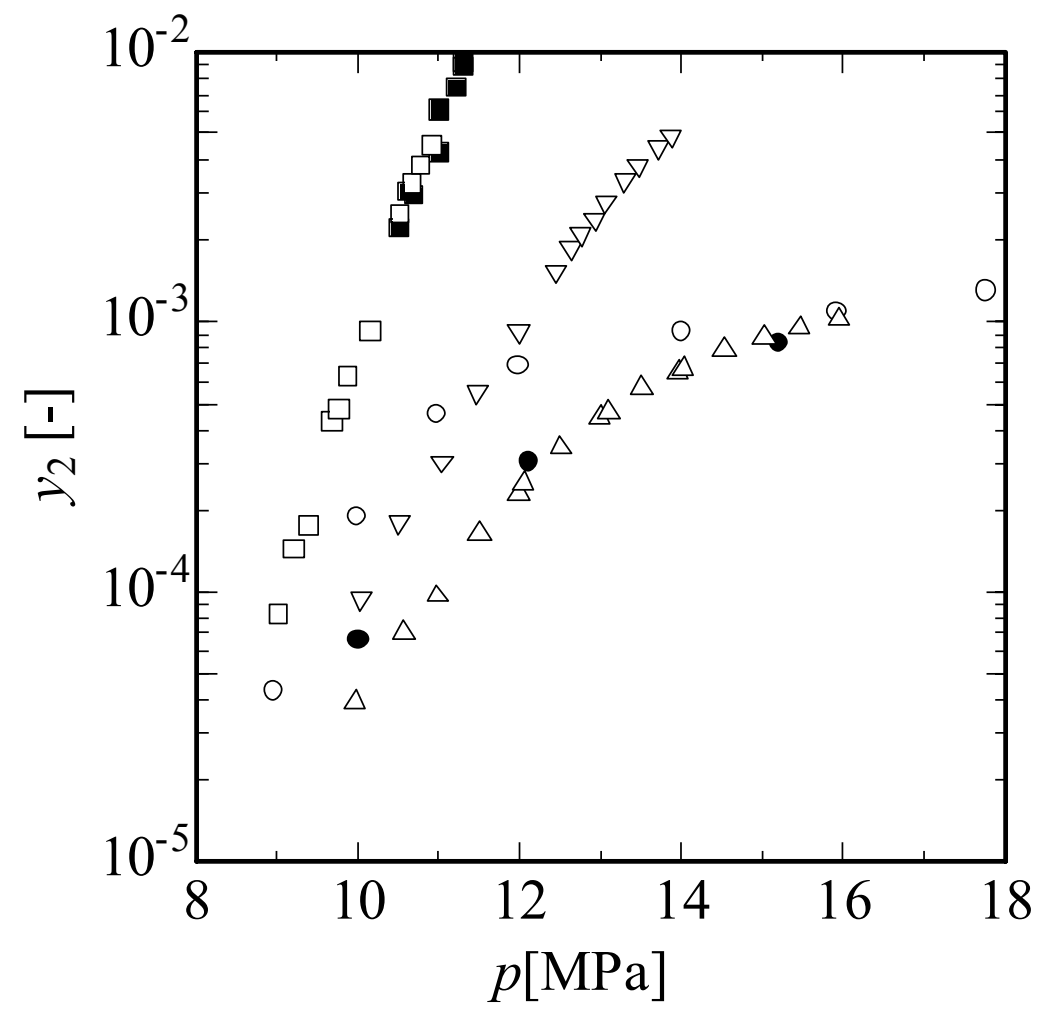

Figure 6 


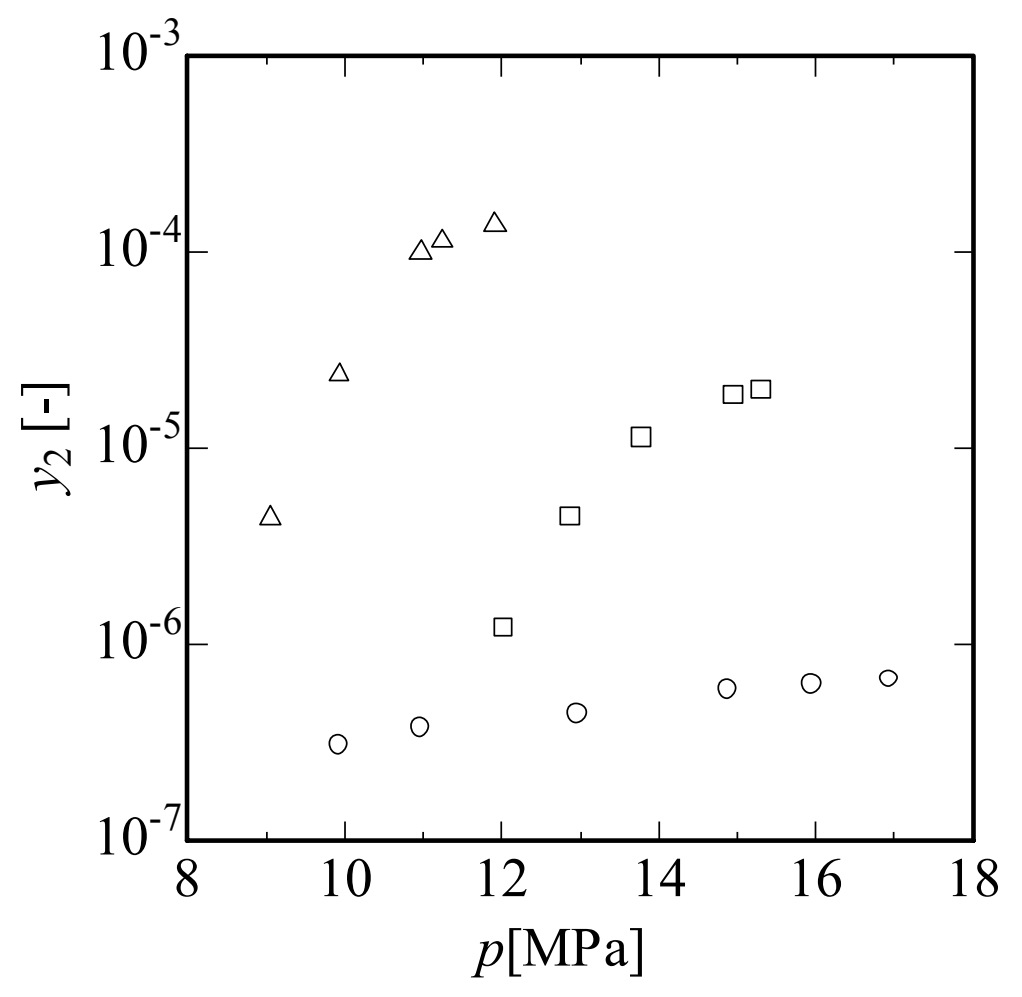

Figure 7 


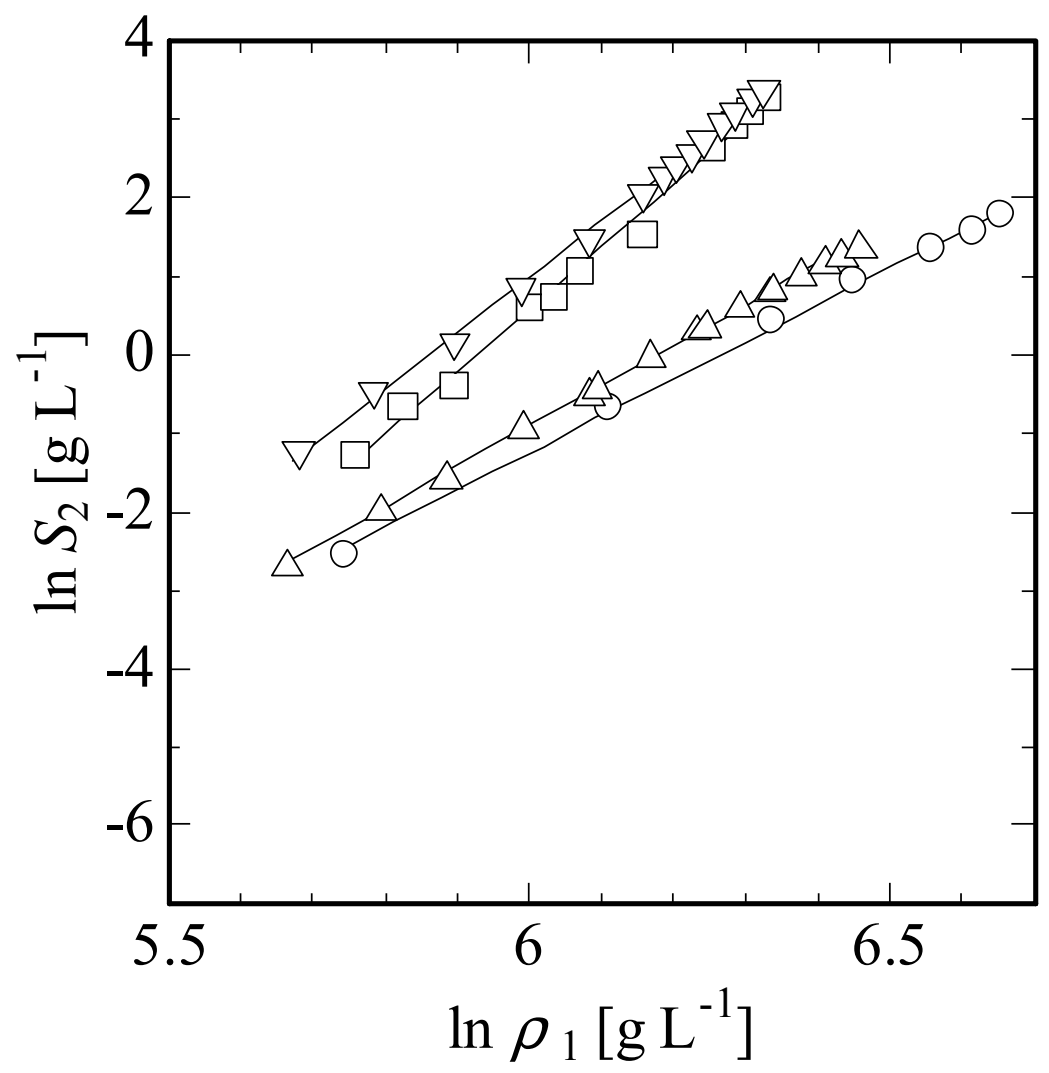

Figure 8 


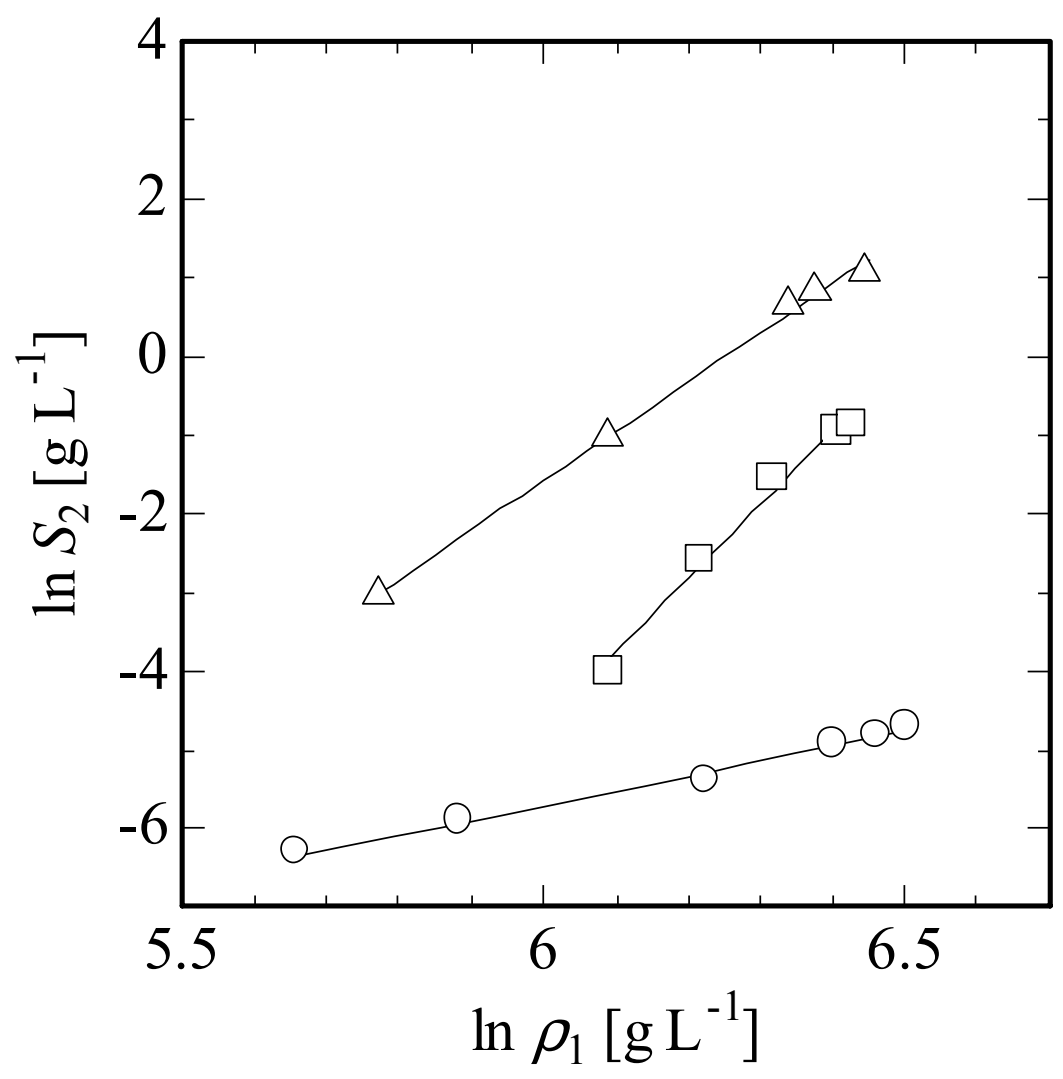

Figure 9 